\title{
Helicobacter pylori infection in patients with Barrett's oesophagus: a prospective immunohistochemical study
}

\author{
O Ricaurte, J-F Fléjou, C Vissuzaine, D Goldfain, A Rotenberg, G Cadiot, F Potet
}

\begin{abstract}
The prevalence of Helicobacter pylori infection in patients with Barrett's oesophagus was studied prospectively. A sensitive immunohistochemical staining of $H$ pylori was performed in oesophageal and gastric biopsies of $\mathbf{7 3}$ patients from a surveillance group with this condition. $H$ pylori was detected in 11 cases of Barrett's mucosa (15\%) and in 26 gastric mucosa specimens $(35 \cdot 6 \%)$. All cases positive in Barrett's mucosa were also positive in the stomach. In Barrett's oesophagus, $H$ pylori was never found on specialised epithelium. The percentage of Barrett's mucosa showing inflammatory changes was similar in specimens with and without $H$ pylori, both for chronic $(81 \% v 79 \%)$ and acute $(9 \% v 10 \%)$ infiltrates. These results indicate that $\boldsymbol{H}$ pylori infection does not play an aetiological role in Barrett's oesophagus and that colonisation of the metaplastic mucosa by this bacteria is related with the presence of gastric type mucosa in the oesophagus and of $\boldsymbol{H}$ pylori infection in the stomach.
\end{abstract}

(f Clin Pathol 1996;49:176-177)

Keywords: Barrett's oesophagus, Helicobacter pylori, immunohistochemistry.

Bichat-Claude

Bernard Hospital,

Paris, France:

Department of

Pathology

O Ricaurte

C Vissuzaine

F Potet

Department of

Gastroenterology

G Cadiot

Department of

Pathology, Beaujon

Hospital, Clichy,

France

J-F Fléjou

Department of Gastroenterology, Dreux Hospital, Dreux, France D Goldfain

A Rotenberg

Correspondence to: Dr J-F Fléjou, Service d'Anatomie et de Cytologie d'Anatomie et de Cytologie Beaujon, F-92118 Clichy

Cedex, France.

Accepted for publication 5 September 1995
Barrett's oesophagus is a pathological condition characterised by the replacement of squamous lining epithelium of the distal oesophagus by columnar epithelium of gastric or intestinal type. This condition used to be a complication of gastroesophageal reflux. Histologically it has been categorised by Paull et al into cardiac or junctional type, fundic type, and intestinal or specialised type ${ }^{1}$; in this latter type there is an increased risk of developing oesophageal adenocarcinoma. Since the original description of Helicobacter pylori in the stomach, its presence has been reported in variable proportions in retrospective studies of patients with Barrett's oesophagus, using various diagnostic methods. ${ }^{2-8}$ From these it is clear that controversy persists about the possible role of $H$ pylori in the natural history of Barrett's oesophagus. The aim of this study was to determinate prospectively the frequency of gastric and oesophageal $H$ pylori infection in a group of patients with Barrett's oesophagus included in a surveillance programme by means of a sensitive immunohistochemical method.
Methods

Seventy three patients with a histopathological diagnosis of Barrett's oesophagus who had been included in a surveillance programme since 1992-1994 were selected prospectively. Barrett's oesophagus was defined by the presence of a columnar mucosa in the lower oesophagus, of any type (cardiac, fundic, specialised) when extending to more than $3 \mathrm{~cm}$ above the gastrooesophageal junction, or with at least one area of specialised mucosa for short segments of Barrett's mucosa. ${ }^{9}$ The patients were 57 males and 16 females, age range $28-81$ years. Four quadrant oesophageal endoscopic biopsy specimens at intervals of $2 \mathrm{~cm}$ and a fundic biopsy specimen were taken in each case. Deparaffinised sections were stained with the anti$H$ pylori rabbit primary polyclonal antibody (Dako NB471) diluted 1 in 10. This antibody reacts with heat stable somatic antigens of the whole bacteria. ${ }^{10}$ In the following steps, an avidin-biotin-peroxidase complex procedure enhanced by a microwave pretreatment was used. $H$ pylori chronic antral gastritis was used as a positive control, while negative controls were incubated with TRIS buffered saline (TBS, $\mathrm{pH} 7 \cdot 6$ ). The immunoreaction for $H$ pylori was considered positive when morphologically typical bacteria were seen, located at the surface of the epithelium or in the canaliculi of parietal cells. The presence or absence of chronic inflammation and activity were evaluated.

\section{Results}

Forty four patients (60\%) had specialised Barrett's mucosa on their oesophageal biopsy specimens, associated with gastric-type mucosa in 33 cases, of either cardiac or fundic type. In the remaining 29 cases, only gastric-type mucosa was present in Barrett's oesophagus. $H$ pylori was detected in the oesophageal biopsy specimens in 11 cases (15\%) (10 male and one female patient, age range 28-78 years) and in the gastric biopsy specimens of 26 patients $(35.6 \%)$. All patients with $H$ pylori in Barrett's oesophagus also had the bacteria in gastric biopsy specimens. $H$ pylori was found in the oesophagus only in junctional (10 cases) and fundic (one case) types of metaplastic mucosa and never in the specialised type mucosa. The percentage of specimens of Barrett's mucosa showing inflammatory changes was similar in 
Reported series of $\mathrm{H}$ pylori infection in patients with Barrett's oesophagus

\begin{tabular}{lclll} 
& \multirow{2}{*}{$\begin{array}{l}\text { No of } \\
\text { Author (ref) }\end{array}$} & \multicolumn{2}{l}{ H pylori positive } & \\
\cline { 3 - 4 } & patients & Stomach & Barrett's & Diagnostic method \\
\hline Talley $^{2}$ & 23 & & $12(52 \%)$ & Warthin-Starry \\
Paull $^{3}$ & 26 & $10(38 \cdot 4 \%)$ & $4(15 \cdot 4 \%)$ & Giemsa \\
Houck $^{4}$ & 34 & & 0 & Giemsa \\
Fallingborg $^{5}$ & $46^{\mathrm{a}}$ & & $12(26 \%)$ & Culture \\
Walker $^{6}$ & $133^{\mathrm{b}}$ & & $6(4 \cdot 5 \%)$ & Culture \\
Francoual $^{7}$ & 7 & & $2(29 \%)$ & Culture \\
GOSPE $^{8}$ & 11 & $4(44 \cdot 4 \%)$ & 0 & Culture \\
Present series & 100 & & $19(19 \%)$ & Warthin-Starry, Giemsa \\
\hline
\end{tabular}

'Biopsy specimens after gastroscopy.

${ }^{b}$ Biopsy specimens before gastroscopy.

specimens with and without $H$ pylori, both for chronic $(81 \% v 79 \%)$ and acute $(9 \% v 10 \%)$ infiltrates.
Discussion
$H$ pylori infection plays an important role in the aetiopathogenesis of chronic gastritis, duodenal and gastric ulcers, and gastric carcinoma. How- ever, its potential role in Barrett's oesophagus has not been completely defined. The detection rate of the bacteria using different techniques has been reported at between $0 \%$ and $52 \%$ in cases of Barrett's oesophagus, ${ }^{2-8}$ while its presence in the stomach has been reported at between $38 \%$ and $44 \%$ in the same patients (table).$^{37}$ In the present study the frequency of $H$ pylori was low in oesophageal biopsy specimens $(15 \%)$ as well as in gastric biopsy specimens $(35 \cdot 6 \%)$. Specialised metaplastic epithelium was not colonised by the bacteria

and the presence of $H$ pylori in the oesophagus was always associated with gastric infection. This finding has been reported previously in retrospective studies ${ }^{7813}$ indicating that $H$ pylori colonisation of Barrett's mucosa is probably a consequence of gastric infection. We did not find any differences regarding the inflammatory changes in oesophageal biopsy specimens of patients either with or without $H$ pylori. We conclude from our results that $H$ pylori does not play an important role in Barrett's oesophagus; its presence in the metaplastic oesophageal mucosa needs the presence of a gastric-type mucosa in the oesophagus, together with a gastric infection.

1 Paull A, Trier JS, Dalton MD, Camp RC, Loeb P, Goyal RK. The histologic spectrum of Barrett esophagus. $N$ Engl IMed 1976;295:476-80.

2 Talley NJ, Cameron AJ, Shorter RG, Zinsmeister AR, Phillips SF. Campylobacter pylori and Barrett's oesophagus. Mayo Clin Proc 1988;63:1176-80.

3 Paull G, Yardley JH. Gastric and esophageal Campylobacter pylori in patients with Barrett's esophagus. Gastroenterology 1988;95:216-8.

4 Houck JA, Lucas JG. Absence of Campylobacter-like organisms in Barrett's esophagus. Arch Pathol Lab Med 1989; 113:470-2.

5 Fallingborg J, Agnholt J, Moller-Petersen J, Christensen LA, Lomborg S, Sondergaard G, et al. Campylobacter pylori in esophagus. Dig Dis Sci 1989;34:1802-3.

6 Walker SJ, Birch PJ, Stewart M, Stoddard CJ, Hart CA Day DW. Patterns of colonisation of Campylobacter pylori in the oesophagus, stomach and duodenum. Gut 1989; 30:1334-8.

7 Francoual S, Lamy Ph, Le Quintrec Y, Luboinski J, Petit JC. Helicobacter pylori: has it a part in the lesion of the gastroesophageal reflux? F Infect Dis 1990;162:1414.

8 Gruppo Operativo Per Lo Studio Delle Precancerosi Esofagee (GOSPE). Helicobacter pylori in Barrett's oesofagee (GOSPE). Helicobacter pylori in

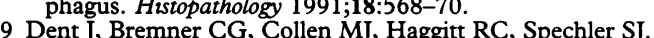
Bent J, Bremner CG, Collen MJ, Haggitt RC, Spechler SJ. Barrett's oesophagus. $f$ Gastroenterol Hepatol 1991;6:1-22.
Andersen LP, Holck S, Poulsen CO. Campylobacter pylori detected by indirect immunohistochemical technique. APMIS 1988;96:559-64.

\title{
Use of buffered formaldehyde in the enzymatic digestion of inflamed mucosa
}

\author{
J Meenan, D O Obradov, H van Dullemen, G N J Tytgat, S J H van Deventer
}

Department of Gastroenterology and Hepatology, Academic Medical Centre, University of Amsterdam, Amsterdam, The Netherlands

Correspondence to: Dr J Meenan, Dr J Meenan, Gastroenterology and Gastroenterology and Mepatology, Aca Meibergdreef 9, 1105 AZ Meibergdreef The Netherlands.

Accepted for publication 20 July 1995

\begin{abstract}
Mucosal inflammation is associated with altered expression of cell membrane molecules. Disaggregation of tissue for flow cytometry may introduce artefactual changes. In an attempt to prevent the induction of artefacts, cells were fixed prior to isolation. The addition of $0 \cdot 1 \%$ buffered formaldehyde to the collagenase/dispase digestion of mucosal biopsy specimens from patients with inflammatory bowel disease enhances detection of CD3, CD11b, CD16, CD63, and CD14. No significant effect was noted for CD19, CD67 or CD45. The expression of CD3, CD11b and CD45 correlated with the degree of endoscopic inflammation. Dilute buffered
\end{abstract}

Flow cytometry is more flexible than standard immunohistochemistry, both in terms of cell numbers analysed and the combination of antigens examined. However, prior to analysis, tissue samples must be disaggregated by mechanical, ion chelation or enzymatic methods. ${ }^{12}$ 